\title{
El holograma como fuente documental y recurso particular de información
}

\author{
Aylén Pérez-Borges*
}

Resumen: Aborda aspectos teóricos y conceptuales de la holografía, y hace referencia a algunos antecedentes en la literatura que la vinculan con las Ciencias de Información, enfatizando en su uso desde esta perspectiva. Se analizan las particularidades del holograma como fuente de tipo documental desde distintas tipologías que se presentan como anexos, análisis que hasta el momento no se ha hecho en ninguno de los trabajos consultados. Se consideran las distinciones del holograma respecto a otros recursos y sistemas de almacenamiento de información además de la fotografía, que es el tipo de documento más similar a un holograma. Es un artículo que informa y orienta al profesional de la información sobre el adecuado uso de este recurso, y para que el mismo sea explotado por sus potencialidades en el almacenamiento y recuperación de información que cumplimentan la misión de bibliotecas, museos y centros de documentación en general.

Palabras clave: Holograma, holografía, fuente de información, fuente documental, documento, recurso de información.

\section{The hologram as a document and unique information resource}

Abstract: The article addresses the theoretical and conceptual aspects of holography and makes reference to earlier references in the literature relating it to information sciences. The specific characteristics of the hologram as a document-like source are analyzed from different typologies, presented as annexes. To date, no such analysis has been made in any of the consulted works. The author examines the differences between holograms and other information resources and storage systems, in addition to the photograph, the type of document most similar to the hologram.

The article attempts to inform and to orient the information professional in the appropriate use of this resource, in order that the potential of holograms for information storage and retrieval can be exploited in the service of the mission of libraries, museums and documentation centers in general.

Keywords: Hologram, holography, source of information, documentary source, document, unique resource.

* Centro de Información Científico-Técnica de la Universidad de Cienfuegos, Cuba. Correo-e: aborges@ucf.edu.cu, kmartinez@ucf.edu.cu.

Recibido: 09-06-2010; 2. ${ }^{a}$ versión: 14-06-2010; 3. ${ }^{a}$ versión: 17-12-2010; aceptado: 04-03-2011. 


\section{Introducción}

Con la aplicación de las nuevas tecnologías de la información y la comunicación en los sistemas de información, las organizaciones actuales han logrado obtener una mayor atracción de su público. Los bibliotecólogos han pasado a ser figuras imprescindibles en la sociedad moderna por la necesidad que existe de informarse sobre los productos más novedosos de la industria en general.

La potencialidad del uso de los vastos depósitos de información derivados del avance tecnológico posee un valor que puede superar actualmente su uso real por el público.

Los soportes tradicionales hoy son desplazados debido a las posibilidades que ofrece la información digital y virtual, que identifica más a los usuarios con la realidad que viven, tal es el caso de los discos magnéticos, ópticos, memorias semiconductoras y memorias holográficas.

A diferencia de los sistemas mencionados, la holografía ha logrado revolucionar los conceptos de grabación y almacenamiento de información, al permitir guardar no sólo en su superficie, sino también en su interior, de forma tridimensional.

Las potencialidades de la técnica holográfica, que propician disímiles usos en la sociedad, ha motivado a realizar un estudio específico del tema en el campo de las Ciencias de la Información, ya que se considera existe un abordaje insuficiente en esta área, aún cuando suele aplicarse y difundirse en la museología a nivel internacional.

Este artículo propone considerar cuáles son las particularidades del holograma como fuente documental y como recurso específico de información.

Se encuentran pocos antecedentes sobre el holograma como recurso de información, ya que por sus disímiles usos, los mismos encuentran vida en otras investigaciones de tipo técnico, como en trabajos de óptica y física en general.

Algunos autores han analizado el tema enfocándose en la Documentación, aunque no se encuentran suficientes antecedentes que caractericen al holograma específicamente como fuente documental. Algunos trabajos de García (García, 2004, 2005), sirven de base para entender al holograma como documento específico.

Es razonable pensar que los hologramas trasciendan, por los atributos que posee como recurso de información, como su capacidad de almacenamiento; su poder de transmisión y las posibilidades de un acceso más rápido, lo que se corresponde con la ambición de una recuperación eficaz por parte de usuarios e intermediarios de la información.

\section{Aspectos teóricos conceptuales de la holografía}

A pesar de llevar más de cuatro décadas de creada, la holografía es una técnica que despierta curiosidad por lo que el presente trabajo brinda una nocion general que puede aclarar las dudas de los lectores sobre su esencia. 
La holografía puede ser descrita como herramienta didáctica y de marketing en bibliotecas, archivos y centros de documentación, como un innovador y eficaz soporte documental y a la vez como un amplio sistema de almacenamiento y recuperación de la información. "Es una nueva vía para almacenar y reproducir información gráfica de forma tridimensional, que en los últimos años ha ganado gran reconocimiento como una herramienta científica para investigaciones y otros propósitos" (Markov, 1992).

Según la Real Academia Española (2001) "la holografía es una técnica fotográfica basada en el empleo de la luz coherente producida por el láser. En la placa fotográfica se impresionan las interferencias causadas por la luz reflejada de un objeto con la luz indirecta. Iluminada (después revelada) la placa fotográfica con la luz del láser, se forma la imagen tridimensional del objeto original».

Puede definirse como un "método de obtener imágenes fotográficas tridimensionales. Las imágenes se crean sin utilizar lente, por lo que esta técnica es conocida como fotografía sin lente. Las grabaciones reciben el nombre de hologramas (en griego, holos, "todo"; gram, "mensaje o cosa escrita")" (Díaz, 2004).

En el artículo Holografía se explican las dos fases en que puede dividirse la técnica holográfica:

La primera de ellas tiene por objeto la obtención de un registro del frente de onda, llamado holograma. La segunda consiste en la reproducción del frente de onda original en ausencia de los objetos que lo originaron.

Un holograma contiene más información sobre la forma de un objeto que una fotografía simple. Este recurso brinda la posibilidad de verla en relieve, por ejemplo, permite percibir de un rostro los dos perfiles y la cara. Esto se observa a medida que el espectador va desplazándose a su alrededor. Igualmente se puede distinguir la profundidad del objeto que ha sido holografiado, así como las zonas de luz y sombra del mismo en el momento que se registró. Tal parece que la realidad se encuentra detrás de la placa holográfica y es difícil resistir la tentación de tocarla.

Con una fuente única de luz blanca, la imagen se reproduce y aparece en tres dimensiones. Esta puede proyectarse dentro o formarse fuera del soporte material en el momento de su reconstrucción" (García, 2004). Se explica además que la holografía no es una técnica para soportar imágenes, sino que es un nuevo modo de grabación, almacenamiento y recuperación de información óptica, es decir, información producida por las ondas de luz.

La holografía es una realidad virtual «La realidad virtual nos permite estar inmersos en una dimensión donde regularíamos sonidos que desvían la atención, permitiéndonos al mismo tiempo concentrarnos mejor en una lectura textual, gráfica, sonora y dactilar. El usuario interactúa con objetos (textos, imágenes, sonidos) en un entorno tridimensional" (Ronda, 2005).

La utilización del láser como fuente de iluminación fue un logro indiscutible y determinante para la fabricación de hologramas en la década de los 60, donde se realizó la primera producción real de hologramas. La técnica se recono- 
ció finalmente en 1962. Con la aplicación del haz láser se observaron imágenes más grandes, nítidas y con mayor ángulo de visión desde varios puntos de vista.

Por su desarrollo y aplicaciones, la holografía ha llegado a ser una de las ramas más importantes de la óptica moderna, pero no se limita a esta rama. Su progreso en el dominio de la acústica evidencia importantes usos en la microscopía, interferometría, geofísica y arqueología.

Es un recurso idóneo para numerosos fines, comerciales, industriales y publicitarios, además de usarse como medio de expresión y creación artísticas.

En la actualidad, la técnica es muy utilizada en el proceso de enseñanzaaprendizaje en los campos de la medicina, educación, computación, minería, biología y en física. No se encuentran en la literatura muchos antecedentes que aborden el tema paralelamente con los estudios en el sector educativo.

\section{Sector de la información}

\subsection{Museología}

Se realizan exhibiciones temáticas en los museos que combinan objetos reales con réplicas holográficas. La exhibición de piezas arqueológicas o de mucho valor en estos centros mediante el uso de la holografía, logra tanto realismo que sólo un experto puede distinguir la diferencia.

Los hologramas sustituyen ventajosamente las copias de obras en centros museológicos. La utilización de la holografía en este tipo de institución tiene como objetivo la preservación visual de objetos valiosos desde el punto de vista histórico, y su recopilación para las instituciones que no pueden acceder a la pieza museable original. Permiten además el intercambio cultural entre museos provinciales, nacionales e internacionales.

\subsection{Almacenamiento de datos}

Permite almacenar datos digitales, que se pueden grabar como puntos brillantes y oscuros en las imágenes holográficas. La holografía multiplexada es la técnica que contribuye a esta aplicación porque permite que muchos hologramas sean almacenados en un mismo cristal en diferentes ángulos.

Un holograma puede contener un gran número de "páginas" que se graban con ángulos distintos respecto de la placa, permitiendo almacenar una cantidad enorme de datos en sí mismo. Iluminándolo mediante un haz de láser, con diferentes ángulos, se pueden recuperar selectivamente las distintas páginas.

La holografía es un instrumento ideal para fabricar dispositivos de seguridad en las tarjetas de crédito o billetes de banco, con hologramas prensados. 


\section{El holograma en torno a los conceptos fuente de información y documento}

Es necesario partir de algunos conceptos y esquemas para afirmar que los hologramas pueden considerarse una fuente de información de tipo documental. El contexto actual sobre los niveles de la información y el desarrollo de las ciencias informacionales, presuponen un cambio en los conceptos tradicionales de fuentes de información. (Reyes, 2006).

Las publicaciones adquieren una nueva dimensión, y se vislumbran otras posibilidades con la realidad virtual. (Rodríguez, 2000).

Carrizo (Carrizo, 2000), brinda una idea específica sobre las fuentes informacionales: «en la definición tienen cabida todos aquellos elementos que, sometidos a la interpretación, pueden transmitir conocimiento, tal como un jeroglífico, una cerámica, un cuadro, una fotografía, un discurso, un libro, una tesis doctoral, etc."

Se suelen confundir con frecuencia los conceptos "documento" y "fuente de información", pero a pesar de la confluencia que existe entre ambos elementos, es muy importante tenerlos bien delimitados. El documento es un tipo de soporte que utiliza la fuente para registrar la información, para que pueda ser mejor difundida (de forma escrita, sonora, simbólica, etc.). A diferencia de la fuente, el documento puede ser procesado (catalogado, indizado, etc.) y preservado según el tipo de material (papel, plástico, etc.).

Cruz (1994), explica que existen diferentes fuentes informacionales, entre las que prevalecen las documentales y no documentales (personales, institucionales, materiales). Estas últimas no se representan en el presente artículo porque no se consideran de interés. Constituyen simplemente entidades de las cuales se obtiene información, pero no pueden incluirse como parte de una colección, lo que no se corresponde con las particularidades del holograma como fuente, que indiscutiblemente puede formar parte de una recopilación, al ser preservado con el objetivo de exponer información.

A pesar de que todas las fuentes poseen la función de generar o suministrar información, los documentos son de por sí más consultados que las fuentes no documentales, y puede otorgársele una mayor importancia si se parte de que una persona o entidad informativa obtiene la información o adquiere los conocimientos de otras fuentes que son en esencia documentos.

Documento: Es toda fuente de información física que comunica como inscripciones, imágenes, sonido, texto, objetos con indicios de intervención humana, creaciones artísticas, e incluso materiales naturales. (Otlet, 1934: dispersa por varias partes de su obra).Todo mensaje icónico, gráfico y simbólico incorporado a un soporte, empleado con una finalidad informativa se considera un documento.

Un holograma es tan informativo como un documento común, aunque evidentemente posee una complejidad en su estructura que lo hace diferente, por ejemplo, en el momento de ser procesado. Ambos son fuentes de información, constituyen bases para informarse, son seleccionados, almacenados y recuperados. 
El holograma registra la información de manera diferente. Es otra forma de representación de los contenidos informativos, detrás del cual existen indicios de actividad humana; por lo que se puede considerar tanto una fuente de información como un documento, o más concretamente una fuente documental de información, según el uso que se le desee dar o el fin para el que haya sido creado.

Para que un objeto se convierta en documento es necesario que se realice una transformación en él, debe estar procesado o preservado con un fin representativo y disponible para la investigación, como es el caso de los hologramas aplicados a la museología en distintos países del mundo generalmente representando objetos reales en exposiciones fijas e itinerantes.

\section{Características del holograma como fuente documental}

Un especialista de la información debe conocer como parte de su preparación profesional las características de la gran variedad de documentos que existe en la organización que labora, y estar capacitado para identificar la categoría a que pertenece cualquiera de ellos. Entre las características esenciales de un documento, se encuentran las denominadas físicas (forma, tamaño, etc.) y las intelectuales.

En este trabajo se pretende analizar algunas de las características intelectuales del holograma como fuente documental de información. De por sí, estas características, en sentido general, permiten determinar la forma de manejo y utilización de un documento.

Las fuentes documentales de información, han sido representadas por varios autores. Algunos de ellos se citan en Vizcaya (2002). Estas representaciones, han sido la base del presente trabajo para distinguir algunas categorías importantes a tener en cuenta dentro de las diversas tipologías de documentos, y a partir de ellas, analizar las características específicas del holograma como fuente documental de información.

Se ha tenido en cuenta de una manera muy sutil, dentro de las representaciones expuestas, el nivel de exhaustividad y especificidad con que los autores desglosan las fuentes que adquieren carácter documental.

La representación de fuentes documentarias más perfeccionada resultó ser la de Vinent y Cruz (2002) (anexo I). Se considera además que la misma posee, en relación con las otras presentadas, un mayor nivel de especificidad en cada una de sus categorías documentales, ya que deja una puerta abierta en la que se podría incluir al holograma, porque menciona la tridimensionalidad, que es una de las características distintivas que poseen los materiales holográficos.

No se hace explícita una referencia directa al holograma como fuente de información documentaria, lo que debería exponerse debido a las características particulares que lo diferencian del resto de los documentos. A pesar de ello, teniendo en cuenta este último esquema, puede considerarse que los hologramas son fuentes documentales no textuales, que constituyen otra de las formas en que se puede mostrar contenidos informativos determinados. 
Entre las categorías predominantes en los esquemas anexados se sintetizaron las coincidencias dentro de las tipologías, para analizar las características más importantes del holograma como fuente documental.

Las características documentales del holograma como fuente pueden variar en dependencia de su uso. Es importante especificar que la descripción que se presenta en este artículo, pertenece mayormente a hologramas que se utilizan en museología, aplicación que predomina en Cuba. De esta forma, el holograma constituye una fuente secundaria porque se basa generalmente en un documento original u objeto de la realidad. En la aplicación del holograma como pieza museable, la fuente primaria es un objeto y el holograma es la reproducción icónica del mismo, por lo que lo sustituye efectivamente mediante una imagen que contiene en sí todos los detalles de dicho objeto.

Según su ámbito de difusión se puede catalogar como fuente publicada. Posee una amplia difusión y utilización en varias esferas de la vida cotidiana. Puede ser observada o utilizada por cualquier persona que necesite analizar su contenido o realizar una investigación sobre ella, e incluso ser llevada a varias comunidades como parte de una exposición itinerante y/o para incluirse en un proceso educativo.

Según la forma de expresar el contenido informativo se considera no textual: tridimensional (con imágenes estáticas y en movimiento, en tres dimensiones).

Un factor muy importante a tener en cuenta en el estudio de alguna fuente documental específica de información, lo constituye el objetivo o la razón por la cual ha sido creada dicha fuente.

En el caso de los hologramas utilizados en Cuba, la mayoría ha surgido para conservar huellas de un acontecimiento (lo mismo que otro objeto museable), aunque este tipo de fuente no sólo permite la conservación de dichas huellas, sino también la preservación del verdadero objeto que representa el acontecimiento, o sea, el original. Este último es su principal objetivo.

Los hologramas, utilizados en la sustitución de piezas originales en los museos, poseen esencialmente contenidos de carácter histórico y patrimonial.

\section{Particularidades del holograma como recurso de información}

Un elemento relevante a tener en cuenta en el estudio de las características de las fuentes documentales, es su tratamiento. Esto resulta más claro si se conoce que en la práctica bibliotecológica, las fuentes de información se convierten en recursos informacionales una vez que se enfoquen en cumplimentar la misión de la organización.

Un mismo documento puede considerarse tanto una fuente como un recurso de información, una vez que este ha recibido un tratamiento documental o procesamiento, y se encuentre listo para responder a un servicio. A diferencia de su abordaje como fuente, el holograma ha sido caracterizado antes como recurso particular de información por algunos autores como Serra (2004), García (2000 y 2005) y Boyles (2000). 
Las memorias holográficas poseen una velocidad de transferencia superior a 1.000 bytes por segundo, lo que significa que permite encontrar un dato elegido al azar en menos de 10 microsegundos. Se recupera paralelamente la información en un intervalo de tiempo que puede llegar a $1 \mathrm{~Gb}$ por segundo. Permite alcanzar una capacidad de grabación de Tbytes $/ \mathrm{cm}^{3}$ (Tbyte $=10$ elevado al cubo Gbytes).

Su densidad de almacenamiento excede los 108 bytes por pulgada cuadrada, por lo que se puede almacenar diferente información sobre una misma unidad de volumen, con modificar simplemente para ello el ángulo de la grabación o la longitud de onda, debido a la gran banda ancha que posee.

El hecho de que se puedan guardar diversas informaciones dentro de un mismo holograma, en canales individuales, radica en la gran banda ancha que este recurso posee. Con otras palabras, en un mismo holograma es posible sobreimprimir otros, sin interferirse o perjudicarse.

Permite almacenar la información tridimensional tanto interna como externamente, ya que almacena el volumen, a diferencia de la mayoría de los soporte ópticos y magnéticos que solo pueden guardar los datos en su superficie. Permite guardar ficheros de grandes dimensiones como son los multimedia que presentan elementos de varios tipos (textuales, audiovisuales, etc.).

Permite el almacenamiento permanente de los datos, por lo que la grabación se realiza una sola vez. Esta propiedad demuestra su eficacia en la creación de copias de seguridad.

Almacena toda la información visual que emana de un objeto, detallando film, cubo, sonido y otros elementos, enviando al espectador ondas luminosas idénticas a las que reflejaría el original. La reproducción posee una alta resolución.

Permite la distinción de volúmenes y profundidades, zonas de luz y sombra y asimilación de texturas, lo que acrecienta la impresión de relieve. Permite obtener imágenes con ampliación o reducción del tamaño real de un objeto (Hologramas de imagen enfocada). Permite visualizar efectos no apreciables a simple vista (estados tensionales y deformacionales de los cuerpos del orden de 10-6 m). Esto posibilita la percepción de lo más mínimo. Se logra mediante la holografía de doble exposición.

Goza de una gran profundidad, lo que no depende de la distancia de observación con el punto objeto de la imagen que se reproduce.

Registra uniformemente la información en todo el dispositivo, lo que reduce su deterioro al protegerla de errores producto del polvo y arañazos.

Constituye una técnica de ensayo óptico no destructivo. A través del holograma se ve la imagen tridimensional de un objeto con perspectiva variable según su tamaño.

Se puede lograr el cambio de color de la imagen del objeto al variar la posición de observación (Hologramas de arco iris), lo que resulta impresionante y llamativo para los usuarios y/o espectadores. En la holografía la misma fuente sirve para iluminar el objeto y para producir un fondo coherente.

La información en el holograma se registra como la dirección del rayo que sale de él, donde diferentes direcciones corresponderían a diferentes valores numéricos o lógicos. 
Es un medio de almacenamiento reciclable. Existen materiales holográficos que se pueden grabar y borrar a voluntad, de forma muy rápida y sencilla. No necesita sistemas ópticos, como es el caso de lentes por ejemplo, lo que evita la aparición de distorsiones y aberraciones. Permite seleccionar la información de manera aleatoria.

La capa de almacenamiento de datos de las memorias holográficas está recubierta por arriba y por abajo, como en un sándwich, por una capa de plástico transparente que garantiza la resistencia mecánica y química para soportar datos.

La holografía puede reproducir información de cualquier tipo. Existen discos duros holográficos que guardan imágenes, música, texto, bits. Se puede usar para el registro el sonido (holograma acústico), permitiendo, al igual que con luz, guardar enormes cargas de información.

Para leer la información de un holograma, la placa ya grabada se alumbra con un láser directo que debe iluminarla exactamente en el mismo ángulo que antes de ser registrada. Este proceso se realiza de forma idéntica que en el caso óptico, donde se recupera la imagen.

La holografía es un método que permite guardar mucha información en poco lugar, lo que brinda una medida de la capacidad que posee el holograma como recurso de información en el campo del almacenamiento de datos. Esta peculiaridad se debe a su uso del principio de superposición.

La importancia del holograma, radica fundamentalmente en la solución de problemas de aumento de capacidad de almacenamiento y mantenimiento de velocidad de acceso razonable. Es un sistema que posee datos comprimidos.

Cada pedazo de un holograma puede contener la imagen entera; cada parte contiene información sobre el todo; y el todo también está contenido en cada parte, pero ello depende en gran medida de las condiciones en que fue creado: distancia del objeto al mismo y difusión de la luz por todo este objeto que se va a holografiar. (Vieira y Ferreira, 2006). Esta característica se puede comprender mejor si toma como ejemplo el holograma de una rosa que es cortado a medias y luego iluminado por un láser. Así se puede descubrir que cada mitad todavía contiene la imagen entera de la rosa. Si se continúa dividiendo las dos mitades, se ve que cada minúsculo fragmento de película siempre contendrá una versión más pequeña, pero intacta, de la misma imagen. (SuGar, 2005).

Muchas de las particularidades y ventajas del recurso se deben a las estrictas exigencias del material polimérico como soporte de datos, que tiene que cubrir un amplio margen dinámico, ser transparente y muy sensible a la luz, dimensionalmente estable y resistente a los cambios de temperatura.

Debido a las características y peculiaridades de los hologramas, los laboratorios de investigación están perfeccionando polímeros especiales para adecuarlos a la producción de soportes de datos con capacidades de hasta 1,6 terabites (1.600 gigabites). Este gigantesco volumen de datos corresponde a 780 millones de páginas DIN-A4 escritas, lo que equivale a los fondos de una gran biblioteca con unos cuatro millones de libros. En uno de estos discos holográficos de polímero también cabrían 1.6 millones de fotografías de alta resolución. Un teleespectador podría uti- 
lizarlo para ver películas sin parar durante 10 días seguidos, y un aficionado a la música podría sentarse ante su cadena musical durante año y medio sin cambiar de disco.

La holografía se ha incorporado en la televisión y el cine, mediante pantallas en tres dimensiones que hacen que los filmes resulten más impresionantes para los espectadores, logrando un ambiente de inmersión, sumergiendo al individuo en las escenas cinematográficas.

Las particularidades de la holografía no sólo permite que la técnica logre potenciarse en el campo informacional y para el futuro, se pueden distinguir también algunas limitaciones:

Existen objetos que no pueden ser holografiables, esto se debe a varias características, entre las que prevalece el poco reflejo de las zonas de luz y sombra. Igualmente se hace limitada la realización de hologramas de objetos con mucha profundidad.

Para reconstruir la imagen holográfica se necesita una fuente de luz blanca puntual o con filamento estrecho, lo que resulta un inconveniente por lo difícil que es de conseguir. La causa se debe a que con estas características se evita la reproducción de varias imágenes al mismo tiempo.

No es posible actualizar los datos que posee un holograma sin regrabar todo su contenido, por lo que no se puede modificar solamente una parte debido a sus características de redundancia.

Los hologramas poseen un ángulo de visión relativamente restringido. Existe un lugar idóneo de visión de la imagen, cuya calidad depende de la posición del observador.

Existen dificultades para conseguir algunos de los materiales para la grabación holográfica, como son los cristales de buena calidad óptica y fotopolímetros de gran tamaño y/o espesor.

En la actualidad la implementación de la técnica holográfica es sumamente cara, y la obtención de hologramas posee un elevado costo comercial.

\section{Características distintivas del holograma respecto a otros recursos y sistemas de almacenamiento de información}

Aunque se encuentran otras técnicas similares a la holografía, empleadas en la producción de dispositivos de almacenamiento y conservación de documentos en general, la fotografía y la microfilmación constituyen básicamente las que más se identifican con ella debido a sus características.

A continuación se muestran las tablas comparativas I y II, sobre diversos recursos de información y otros sistemas de almacenamiento de información.

Mediante los datos ofrecidos se demuestra la capacidad que posee el holograma para almacenar y transferir información respecto a otros recursos y sistemas que son mayormente utilizados. 
TABLA I

Comparativa de los recursos de información

\begin{tabular}{|c|c|c|c|c|}
\hline Recursos & Almacenamiento & $\begin{array}{l}\text { Resolución } \\
\text { del material }\end{array}$ & Soporte & $\begin{array}{l}\text { Representación } \\
\text { de la información }\end{array}$ \\
\hline Fotografía & $\begin{array}{l}\text { Información relacio- } \\
\text { nada con la intensi- } \\
\text { dad de la luz }\end{array}$ & Baja & $\begin{array}{l}\text { Necesita un negativo } \\
\text { aparte para la infor- } \\
\text { mación sobre las in- } \\
\text { tensidades de la luz } \\
\text { de cada objeto regis- } \\
\text { trado }\end{array}$ & $\begin{array}{l}\text { Representa imáge- } \\
\text { nes estáticas bidi- } \\
\text { mensionales (pla- } \\
\text { nas) }\end{array}$ \\
\hline Microfilme & $\begin{array}{l}\text { Información relacio- } \\
\text { nada con la intensi- } \\
\text { dad de la luz }\end{array}$ & Baja & $\begin{array}{l}\text { Necesita un negativo } \\
\text { para conservar la in- } \\
\text { formación sobre las } \\
\text { intensidades de la } \\
\text { luz de cada objeto } \\
\text { registrado }\end{array}$ & $\begin{array}{l}\text { Representa imáge- } \\
\text { nes estáticas bidi- } \\
\text { mensionales }\end{array}$ \\
\hline Holograma & $\begin{array}{l}\text { Información relacio- } \\
\text { nada con la intensi- } \\
\text { dad de la luz y la } \\
\text { dirección de donde } \\
\text { procede: fase }\end{array}$ & Alta & $\begin{array}{l}\text { Se guarda en un solo } \\
\text { soporte que se mo- } \\
\text { difica al ser visuali- } \\
\text { zado. Es a la vez po- } \\
\text { sitivo y negativo }\end{array}$ & $\begin{array}{l}\text { Representa imáge- } \\
\text { nes bidimensionales } \\
\text { y tridimensionales, } \\
\text { fijas y en movimien- } \\
\text { to }\end{array}$ \\
\hline
\end{tabular}

TABLA II

Comparativa entre el bolograma y otros sistemas de almacenamiento de información (Boyles, 2000)

\begin{tabular}{l|c|c|c|l}
\hline $\begin{array}{c}\text { Tipo } \\
\text { de almacenamiento }\end{array}$ & Capacidad & $\begin{array}{c}\text { Tpo } \\
\mathbf{d e} \text { acceso } \\
\text { (M/seg.) }\end{array}$ & $\begin{array}{c}\text { Tasa de } \\
\text { trasferencia } \\
\text { (Mb/seg.) }\end{array}$ & Grabación/lectura \\
\hline Disco duro (magnético) & $60 \mathrm{a} 100 \mathrm{~Gb}$ & 10 & 15 & $\begin{array}{l}\text { Cabezas mecánicas en } \\
\text { superficie magnética }\end{array}$ \\
\hline DVD & $5 \mathrm{~Gb}$ & 150 & 2 & $\begin{array}{l}\text { Uso del láser sobre la } \\
\text { superficie }\end{array}$ \\
\hline Holograma & $200 \mathrm{~Gb}$ & 2 & 50 & $\begin{array}{l}\text { Interferencia del láser en } \\
\text { todo el material }\end{array}$ \\
\hline
\end{tabular}

\section{Conclusiones}

Una vez analizadas las particularidades del holograma como fuente documental y recurso particular de información resultan notables los datos relevantes a su capacidad de almacenamiento, con un bajo costo en este sentido, independientemente de su alto valor comercial. 
Se puede afirmar con toda seguridad su importancia en la conservación y preservación, al lograr un alto nivel de precisión si se compara con una fotografía o un microfilme y habiendo conocido el uso que se le da en museología.

\section{Bibliografia}

Boyles, S. (2000). Holographic Memory [en línea], disponible en: http://ucsu.Colorado. edu/ stephanb/projects/CSI3300.htm [consultado el 26 de noviembre de 2001].

Carrizo, G. (2000). Manual de Fuentes de Información. Zaragoza.

Cruz, A. (1994). Fuentes de información: aspectos teóricos. La Habana, Universidad de La Habana.

Díaz, C. (2004). Holografía [en línea], disponible en: http://perso.wanadoo.es/chyryes/ glosario/holograf.htm [consultado el 22 de octubre de 2007].

García, L. (2000). "Sistemas de información: La holografía en el mundo de la documentación" en: El profesional de la Información. Volumen 9, número 4, abril, pp. 20-40.

García, L. (2004). La bolografía boy. Nuevos documentos del futuro [Cuaderno Digital], pp. 1-15.

García, L. (2005). "Las memorias holográficas como nuevo soporte de documentos audiovisuales" en: Investigación Bibliotecológica, vol. 20, n. ${ }^{\circ} 41$, julio-diciembre 2006. México, pp. 141-160.

Markov, V., y Javtuschenko, I. G. (1984) Holography and its applications in museum work. Studies and Documents on the Cultural Heritage, n. ${ }^{\circ} 5$ UNESCO, París.

Markov, V. (1992). "Holography in museums-why not go 3D?» en: Museum. Volumen 44, n. ${ }^{\circ} 174$, pp. 83-86.

Otlet, P. (1934). Traité de Documentation. La livre sun le livre.Théorie et practique. Brucelas, Mundaneum.

Real Academia Española (2001). Diccionario de la Lengua Española. Tomo II, vigésima segunda edición, Madrid.

Reyes, L. (2006). Manual de fuentes de información. La Habana, Editorial Pueblo y Educación.

Rodríguez, M. A. (2000). Retos del editor científico contemporáneo. Tesis de licenciatura. La Habana, Facultad de Comunicación, Universidad de La Habana.

Ronda, R. (2005). Productos Electrónicos principios y pautas. La Habana, Editorial Félix Varela.

Serra, R. (2004). "El Holograma y la metodología para su construcción en Cuba” en: La utilización del holograma como un medio de enseñanza y de educación social en Cuba como resultado del vínculo investigación, docencia y extensión universitaria. Tesis de doctorado. La Habana, Departamento de Física, ISPJAE, pp. 33-65.

SuGar. (2005). Tecnologías de Realidad Virtual crean Libros con Hologramas Multimedia en $3 D$ [en línea], disponible en: http://sirmijail.blogspot.com/2005/03/tecnologas-derealidad-virtual-crean.html [consultado el 26 de noviembre de 2007]. 
Vieira, H., y Ferreira, L. (2006). "La Holografía”. Ciencia y Sabiduría [en línea], disponible en: http://www.revistabiosofia.com/index.php?option=com_content\&task=view\&id=11 $5 \&$ Itemid $=40$ [consultado el 2 de septiembre de 2007].

Vincent y Cruz citado por Vizcaya, D. (comp.) (2002). Selección de lecturas. Fundamentos de la organización de la información. Impreso por Servigraf.

Vizcaya, D. (comp.) (2002). Selección de lecturas. Fundamentos de la organización de la información. Impreso por Servigraf.

\section{Anexo I. Esquemas sobre tipologías de fuentes documentales de información}

Esquema de fuentes documentales, según Vinent y Cruz

(Vincent y Cruz citado en Vizcaya, 2002:42)

\begin{tabular}{|c|c|c|}
\hline \multicolumn{3}{|c|}{ Fuentes informacionales I } \\
\hline \multicolumn{3}{|c|}{$\begin{array}{l}\text { Fuentes documentales } \\
\text { En cuanto a }\end{array}$} \\
\hline $\begin{array}{l}\text { Soporte material } \\
\text { - Papel (libros, revistas) ex- } \\
\text { presión del contenido. } \\
\text { - Material químico (pelícu- } \\
\text { las). } \\
\text { - Material magnético (cintas } \\
\text { de video, disquetes). } \\
\text { - Material plástico } \\
\text { - Madera, etc. }\end{array}$ & $\begin{array}{l}\text { Mensaje } \\
\text { — Forma (inéditos, personales). } \\
\text { — Documentos textuales. } \\
\text { - Documentos no textuales } \\
\text { (sonoros, iconográficos, au- } \\
\text { diovisuales, informáticos, } \\
\text { compuestos, tridimensio- } \\
\text { nales). } \\
\text { - Nivel y rigor del contenido } \\
\text { (científicos, técnicos-profe- } \\
\text { sionales, culturales-divulga- } \\
\text { tivos, sociales). } \\
\text { - Transformación del conte- } \\
\text { nido (primarios, secunda- } \\
\text { rios, terciarios, mixtos, que } \\
\text { tienen elementos primarios } \\
\text { y secundarios, como es el } \\
\text { caso de las bibliografías co- } \\
\text { mentadas) }\end{array}$ & $\begin{array}{l}\text { Difusión } \\
\text { - Social (públicos, reserva- } \\
\text { dos, folletos, etc.). } \\
\text { - Temporal (periódicos, no } \\
\text { periódicos) }\end{array}$ \\
\hline
\end{tabular}

